\title{
Comprehensive Information Support of Urban Planning on BIM-based Design
}

\author{
Tetyana Honcharenko $^{1}$, Yevhenii Borodavka ${ }^{2}$, Elena Dolya ${ }^{3}$, Olena Fedusenko ${ }^{4}$, Iryna Domanetska ${ }^{4}$ \\ ${ }^{1} \mathrm{PhD}$ (Engineering), Associate Professor, Department of Information Technology, Kyiv National University of \\ Construction and Architecture, Ukraine, iust511@ukr.net \\ ${ }^{2}$ Doctor of Sciences (Engineering), Professor, Department of Information technologies of design and applied \\ mathematics, Kyiv National University of Construction and Architecture, Ukraine \\ ${ }^{3} \mathrm{PhD}$ in Physics and Mathematics, Associate Professor, Department of Information technologies of design and \\ applied mathematics, Kyiv National University of Construction and Architecture, Ukraine \\ ${ }^{4} \mathrm{PhD}$ in engineering, Associate Professor, Department of intellectual and informational systems, \\ Taras Shevchenko National University of Kyiv
}

\begin{abstract}
The article is devoted to comprehensive information support of urban planning design based on BIM-technology. The study is based on a systematic approach to the process of developing urban planning documentation at the pre-design stage of construction, based on the current modern trend of transition to the digital economy. Information model of the territorial cluster of urban planning design is proposed in the study. The content of each layer of territorial cluster information model is described in detail. The conceptual model of spatial data storage for solving problems of general planning of the territorial cluster is presented in the form of three main blocks. Block 1 is data sources that are taken from the operating system and external sources. Block 2 is a data store, which operational and external sources supply spatial data or metadata. Block 3 is consumers of information that generate requests for data to the means of presenting information. The structure of Unified Information Support Center (UISC) and performers for comprehensive information support of the territorial cluster is presented in the study. As the results of the study are shown summary plan of engineering networks, made using BIM-based design software and digital 3D model of the consolidated plan of engineering networks, made using AutoCAD Civil 3D. The use of BIM technologies at the stage of urban planning design is a new direction of its development.
\end{abstract}

Keywords: BIM technology, software, information support, data storage, spatial information, AutoCAD Civil 3D, urban planning design, Unified Information Support Center.

\section{INTRODUCTION}

Modern trends in the development of systems engineering in the field of construction dictate the need to use and develop innovative approaches to organizing the process at each stage of the life cycle of a construction object. The most famous BIM (Building Information Modeling) technology provides the ability to partially simulate the construction process, creating all the necessary layers with structures, life support systems and information attributes. Such a model is developed at the stage of forming a package of working documentation and is often used in project activities. Its main advantage lies in a systematic approach to the technical organization of a construction project, which allows minimizing the number of errors made during design [1-3]. One of the directions of development of this technology is its spread to other stages of the life cycle, for example, from the pre-design stage of urban planning to the development of working documentation. At this stage, the initial information on the design object is laid: its shape, volumes, spatial planning solution, binding to the relief, networks and infrastructure. Such information is the starting point for further design stages, which determines the relevance of the issue of including this stage in the BIM design process.

To develop a model of information space of integrated planning of territorial clusters of construction projects requires at least the construction of a single computer network, which determines the creation of a single database and all software that automates the process and must work with it in a single automated system.

The amount, structure and detail of information about the land plot is its information potential, which determines the level of its attractiveness to the developer. The adaptation of the land plot to the development goals begins with the planning and placement of elements of the master plan. For each of them, in order to perform its functional purpose, there are certain requirements for placement. For the territorial binding of these elements it is necessary to take into account the factors that affect their location and orientation in space.

\section{LITERATURE REVIEW}

The study is based on a systematic approach to the process of developing urban planning documentation at the pre-design stage of construction, based on the current trend of transition to the digital economy.

Urban planning includes the following stages [4-6]:

- preparation of a technical assignment for a territory planning project;

- development of options for spatial planning solutions for the territory; 
- development of materials to justify the project;

- coordination and approval of urban planning documentation and their transfer to the next design stage.

The use of BIM technology makes it possible to form an information model of the territory, which contains information:

- on the existing and planned use of land plots, as well as information about the copyright holder;

- on regulatory and urban planning documentation that determines the nature of the use of territories, requirements for the placement of facilities, landscaping, planned development, restrictions on territories with special conditions of use, etc.;

- to be entered into the information system for ensuring urban planning activities, including plans for ground and underground communications, the position of the territories of the street and road network, etc.;

- on the cost and timing of work on the development of the territory.

The analysis of literature sources [7-9] allowed classifying the requirements for the layout of the elements of general planning and the main environmental factors that affect their location. The authors of $[10,11]$ propose models by which it is proposed to specify information flows to achieve consistency in all elements of the automated system. In the works of specialists $[12,13]$ the prospects of creating integrated and specialized data warehouses on all aspects of the municipal economy are considered. This topic was further developed in the manuscripts [14-17], in which the infrastructure of three-dimensional spatial data includes the mechanism of accessibility, standardization, accumulation of information exchange, taking into account primarily geodata about the study area by terrain, hydrology, engineering networks and administrative boundaries. The integration of information is formed in such a way that the quality of data is determined at the time of their receipt, rather than application. The content and structure of Data Bases (DB) are formed by digital data on spatial objects. Information support of DB is formed by both primary and secondary data. The accuracy of the primary data determines the resolution parameter when conducting photo fixation, probing, scanning and other types of measurements [18].

\section{MAIN RESEARCH}

The data system required for the formation of the territorial cluster (TC) of urban planning design is given in [14] and shown in the table 1 .

The introduction of such a model of the territory with the objects to be placed and the accompanying infrastructure allows expanding the capabilities of BIM technology and increasing the efficiency of the design and construction process. This model makes it possible to establish relations between the design stages: pre-design, design and the stage of working documentation, which makes it possible to manage the quality of development of territories.

Table 1: Information model of the territorial cluster of urban planning design

\begin{tabular}{|c|c|c|}
\hline \multicolumn{2}{|c|}{ Typical content of the territory planning project } & $\begin{array}{l}\text { Territorial cluster } \\
\text { information model layers }\end{array}$ \\
\hline \multirow{4}{*}{$\begin{array}{l}\text { Stage 1. } \\
\text { Assessment of } \\
\text { the current } \\
\text { situation and } \\
\text { prerequisites for } \\
\text { the development } \\
\text { of the territory }\end{array}$} & $\begin{array}{l}\text { Existing use of the territory and } \\
\text { prerequisites for its development }\end{array}$ & \\
\hline & $\begin{array}{l}\text { The current state and prerequisites for the } \\
\text { development of transport services for the } \\
\text { territory }\end{array}$ & \\
\hline & $\begin{array}{l}\text { The current state and prerequisites for } \\
\text { engineering support of the territory }\end{array}$ & \\
\hline & $\begin{array}{l}\text { Functional planning organization of the } \\
\text { territory }\end{array}$ & \\
\hline \multirow{5}{*}{$\begin{array}{c}\text { Stage 2. } \\
\text { Urban planning } \\
\text { documentation } \\
\text { (project } \\
\text { proposals) }\end{array}$} & $\begin{array}{l}\text { Plan of architectural and planning } \\
\text { organization of the territory }\end{array}$ & \\
\hline & Transport service of the territory & \\
\hline & Engineering support of the territory & \\
\hline & Architectural planning solution & \\
\hline & $\begin{array}{l}\text { Proposals for the preservation, } \\
\text { development and limitation of the use of } \\
\text { land plots in zones with special conditions } \\
\text { of use }\end{array}$ & \\
\hline
\end{tabular}


In the course of studying the possibilities of using BIM-technology in urban planning, the software AutoCAD Civil 3D was used in the implementation of the project for planning the territory.

The work was carried out as part of the final qualifying work. At the same time, the possibilities of the software package were studied for solving problems of developing urban planning documentation, such as:

- formation of a package of documentation for a territory planning project in a single file with the integration of various information layers according to the relevant sections;

- binding the planning solution to the geo-digital terrain model;

- development of interrelated materials to justify the spatial planning solution.

The functional and planning solutions of the territory, made in conjunction with a digital terrain model with data from satellite elevation survey, is shown in information model of the territorial cluster of urban planning.

Binding to elevations of buildings and structures, roadways, utilities allows forming a ready-made planning solution in one file, as well as all accompanying sections for the project stage. This serves as the basis for further BIM-modeling of each of the buildings with vertical and horizontal reference to a specific territory with certain parameters. Thus, a digital model of the projected territory is created, which is the basis for the development of the planning solution itself and the materials for justification, requiring reference to elevation marks and integrated into a single constructive, engineering and technological solution.

In accordance with the developed information model on table 1 , stage 2 of materials for substantiating the functional planning solution for the territory of the educational center includes the following information layers, performed in one digital model of the projected territory.

Information layer № 1 is the scheme of transport services, the development of which includes:

- routing of the road network of the projected territory in relation to the elevation marks of the buildings being placed and the existing relief with the appointment of slopes and parameters of the transverse and longitudinal profiles in accordance with the standards of urban planning;

- linking the entrances-exits from the territory to the external street network;

- automatically built longitudinal and transverse profiles, as well as vertical layout of the road network, output of black and red marks of trays.

Information layer №2 is the scheme of engineering support of the territory with containing:

- the scheme of the vertical planning of the territory with reference to the tracing of the road network and engineering communications;

- a summary plan of engineering networks with marks of laying relative to the red marks of the earth;

- automatically generated cartogram of earth masses. Information layer № 3 is architectural and planning solution of the territory, which includes plans:

- 1st floor and floors located below, requiring the implementation of work underground or at ground level with a height reference to the red marks of the vertical layout of the territory;

- insolation of facades and adjustment of the placement of buildings in the absence of standard lighting times;

- typical floors, roofs, typical section, etc., giving an idea of the functional purpose of the construction object;

- isometric views of facades for visualization of design solutions.

On the example of the educational center, work was carried out to simulate the pre-design stage of urban planning in the development of a territory planning project in accordance with the requirements of the national standard of urban planning. This experience should be considered a contribution to the development of BIM technology in urban planning and the expansion of the modeling field from a specific construction site to its location.

Summarizing the approaches used to form information support in design systems of construction, the conceptual model of spatial data storage for solving problems of general planning of the territorial cluster can be represented in the form of three main blocks, which are presented in Fig. 1.

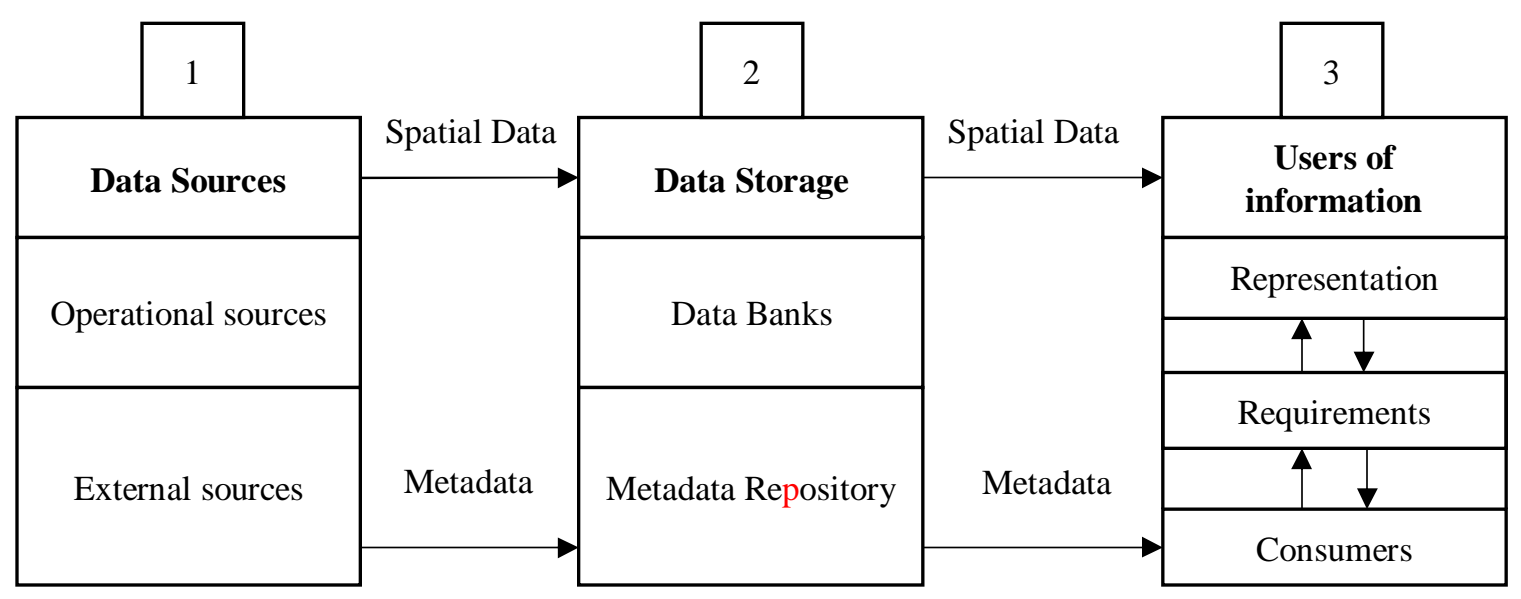

Figure 1: Conceptual model of spatial data storage 
Block 1 is data sources that are taken from the operating system and external sources. Block 2 is a data store, which operational and external sources supply spatial data or metadata. Block 3 is consumers of information that generate requests for data to the means of presenting information, which, in turn, generate a request sent to the data warehouse. The main components of the data warehouse are:

- operational data sources;

- design / development tools;

- means of data transfer and transformation;

- DBMS;

- means of access and data analysis;

- means of administration.
For automated systems of integrated general planning of territorial clusters, it is important to have "feedback" with the data store (DS), which allows to notify the user about the appearance of the required information in the repository and automatically send this information in the form converted to customer data model.

The data bank on organizational preparation of territories should generate information both for operative design decisions, and for the control over already put into operation communications. Therefore, data transfer and transformation services must not only be able to receive and convert information, but also provide (or automatically download) the necessary data from the repository to operating systems in an understandable form and the required data format.

Fig. 2 presents a model of data exchange.

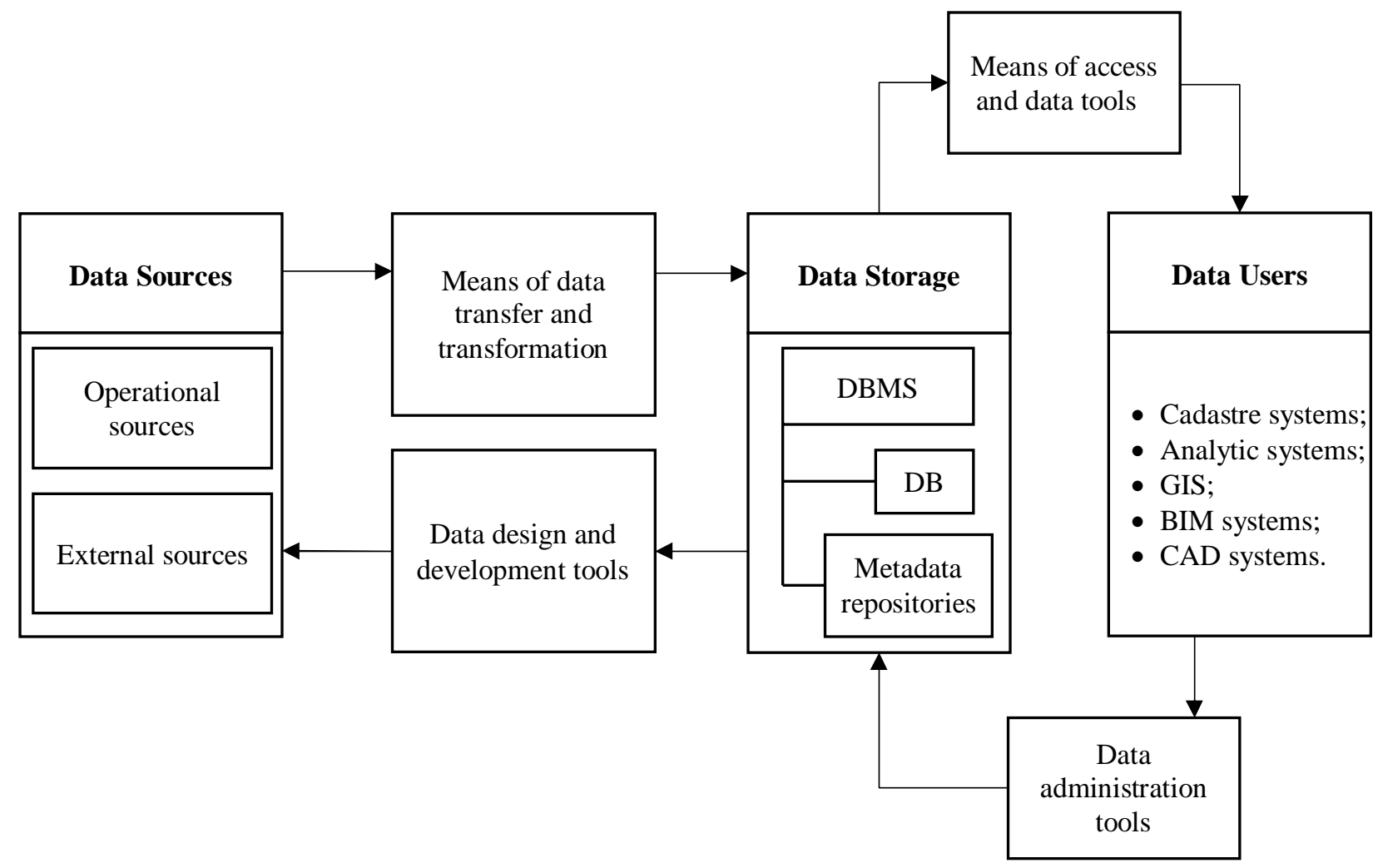

Figure 2: Model of data exchange

Data stores are characterized by multidimensional presentation of information. This structure determines the set of actual and measured data. This is due to the desire to identify individual entities that facilitate business intelligence data from the required information sections of the organization. In contrast to the multidimensional information model of general construction tasks, for the storage of cadastral information of architectural and construction design, the model requires a multilayer, and its main element should be a cadastral object.

The aggregated data on the object will represent an information slice for all layers relevant to the object at a certain point in time. Thus, in the system of organizational preparation for construction, the data warehouse for the subject area of the urban cadastre must meet the following requirements:
- perceive and recognize cadastral information through procedures for extracting, converting and uploading data to the repository;

- to ensure long-term storage of information and keeping a history of its accumulation;

- create and store matching schemes of source operating system metadata and storage metadata;

- provide services for automatic updating of storage data into the operating system, converting information in accordance with the client's metadata;

- protect information from unauthorized access; have an open architecture that is easily integrated and expandable; provide access to metadata and data from analytical information systems.

Thus, the main difference between the data exchange model in Fig. 2 from the traditional storage is determined by the 
purpose of information accumulation: data in the database should be organized in an optimal way not for analysis but for consolidation of information of different automated systems. Thus, a conceptual model of information support of the process of general planning of territories for complex concentrated construction has been developed.

The developed conceptual model of information support of the process of general planning of territories for complex concentrated construction envisages creation of a single methodological and technological base for integrated information space with maximum use of already existing databases and available technical means.

\section{RESULTS AND DISCUSSION}

It is offered to use the software of domestic developer INGCAD, which works in the BIM-environment of AutoCAD Civil 3D on the basis of comprehensive information support for automated creation of the summary plan of engineering networks.

To implement the principle of integrated data processing, a single information base of the system is created, and information links are made through the central service of the system and the computer center interacts with it. The complex of interconnected means of transmission, storage, accumulation and processing of information is the technical basis of such a system, in which the central place is occupied by automation. The workplaces of the project executors are equipped with computers that meet the technical requirements of AutoCAD Civil 3D, integrated into a local network. To perform the work on the design of the consolidated plan of engineering networks, a computer is allocated, which performs the functions of a server, on which a common project directory is created, to which all project participants have access. All work on the project is carried out only in it. As a result of joint work each employee has operative data of a condition of networks of the adjacent are coordinates, diameters, marks in points of intersection. Network work with digital geodetic survey, which is presented in vector 3D-form, is provided. Surveys of networks are in the thematic plan of the organization of projects, are placed on the server where the software product is started, and on other computers local workplaces are opened.

The structure of Unified Information Support Center (UISC) and performers for the provision of spatial information for the organizational training of the territorial cluster is presented in Fig. 3. Users design with the software INGCAD in BIM environment AutoCAD Civil 3D, which automatically interpolates the natural marks of the earth from the substrate opened on the server, recognizes communications passing at acceptable distances detects characteristic points of intersection and assigns design marks to communications. The result of automation is a summary plan of engineering networks. Fig. 4 shows an example of such plan.

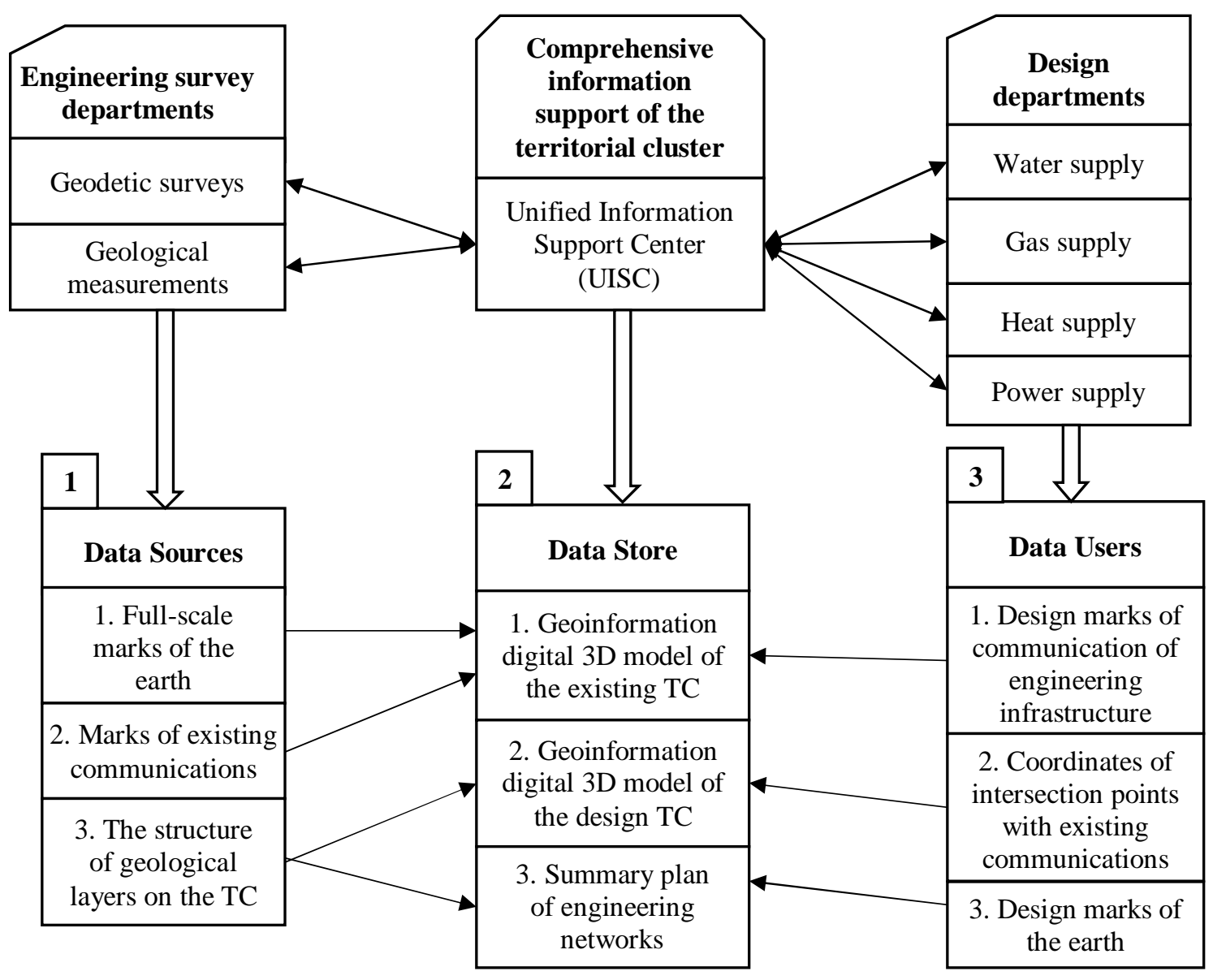

Figure 3: Structure of UISC and executors for providing information support 


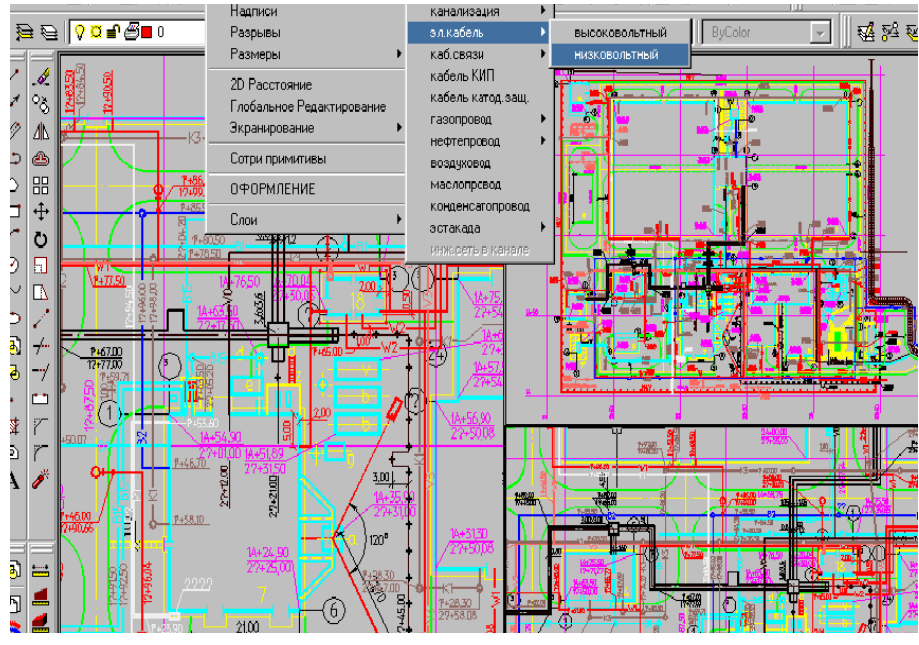

Figure 4: Summary plan of engineering networks, made using BIM-based design software

The practical implementation of the information modeling tool for complex urban planning of territorial clusters of concentrated construction for the development of digital $3 \mathrm{D}$-model of the consolidated plan of engineering networks is carried out on the basis of modern software INGCAD, which works in 3D modeling AutoCAD Civil 3D.

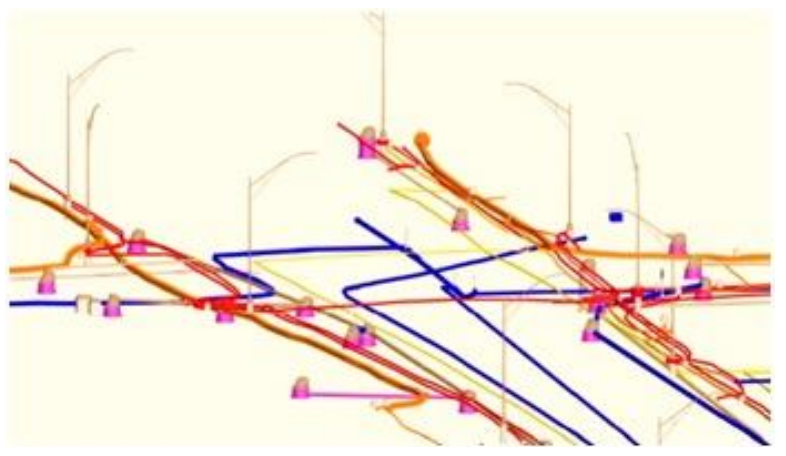

Figure 5: Digital 3D model of the consolidated plan of engineering networks, made using AutoCAD Civil 3D

Databases of information modeling should be developed in a single system for different stages of the life cycle of the territorial cluster, including the following elements:

- formation of information cadastral data;

- geoinformation survey;

- comprehensive urban planning of the territorial cluster for construction, taking into account the factors of influence of the adjacent territories.

\section{CONCLUSION}

At present, the development of the digital economy and systems engineering in construction is prioritized by information cloud technologies aimed at introducing an integrated approach to the construction of buildings and structures at all stages. The use of BIM technologies at the stage of urban planning design is a new direction of its development. It is noted that the design of any object is impossible without its interaction with the territory of location and urban infrastructures. The quality of this interaction will determine not only the effectiveness of the construction solution as a whole, but also the comfort of the urban environment for the users of the facility, which fully corresponds to the modern trends in the development of the urbanized environment.

\section{REFERENCES}

1. T. Honcharenko, Y. Chupryna, I. Ivakhnenko, M. Zinchenco, T. Tsyfra. Reengineering of the Construction Companies Based on BIM-technology, International Journal of Emerging Trends in Engineering Research, 8(8), August 2020, pp. 4166-4172 https://doi.org/10.30534/ijeter/2020/22882020

2. V. Mihaylenko, T. Honcharenko, K. Chupryna, Yu. Andrashko and S. Budnik. Modeling of Spatial Data on the Construction Site Based on Multidimensional Information Objects. International Journal of Engineering and Advanced Technology. Volume-8 Issue-6, pp.3934-3940, August 2019. URL: https://www.ijeat.org/wp-content/uploads/papers/v8i6/F 9057088619.pdf

3. O. Terentyev, S. Tsiutsiura, T. Honcharenko and T. Lyashchenko. Multidimensional Space Structure for Adaptable Data Model, International Journal of Recent Technology and Engineering (IJRTE), Volume-8 Issue-3, pp. 7753-7758, September 2019. URL: https://www.ijrte.org/wp-content/uploads/papers/v8i3/C 6318098319.pdf

4. M. Ahmad, T. Sinelnikova, S. Mustafa, V. Lyashenko. Features of the Construction and Control of the Navigation System of a Mobile Robot. International Journal on Emerging Trends in Engineering Research, 8(4), pp. 1445-1449, April 2020. https://doi.org/10.30534/ijeter/2020/82842020

5. S. A. De Santana. Modeling urban landscape: new paradigms and challenges in territorial representation, Disegnare con., 2013, no. 6(11), pp. 161-174, DOI 10.6092/issn.1828-5961/3379

6. A. Kuchansky, Y. Andrashko, A. Biloshchytskyi, O. Danchenko, O. Ilarionov, I. Vatskel and T. Honcharenko. The method for evaluation of educational environment subjects' performance based on the calculation of volumes of M-simplexes in Eastern-European Journal of Enterprise Technologies, 2 (4-92), pp. 15-25, http://journals.uran.ua/eejet/article/download/126287/12 5235

7. D. Ryzhakov, O. Dikiy, M. Druzhynin, H. Petrenko and T. Savchuk. Innovative tools for management the lifecycle of strategic objectives of the enterprise-stakeholder in construction, International Journal on Emerging Trends in Engineering Research, 8(8), 2020, pp. 4526-4532, https://doi.org/10.30534/ijeter/2020/78882020 
8. I. Arutiunian, M. Poltavets, O. Bondar, V. Anin and F. Pavlov. Structural Information Management of Production Systems in Construction, International Journal of Advanced Trends in Computer Science and Engineering, 9(4), July -August 2020, pp. 4794 - 4797, https://doi.org/10.30534/ijatcse/2020/87942020

9. A.V. Burkov, R.V. Pshenichnov, T.V. Yalyalieva. Construction of models for conversion of mortgage applications by the method of multiple regression and Neural Networks, International Journal of Advanced Trends in Computer Science and Engineering, 9(4), July -August 2020, pp. 4546-4550, https://doi.org/10.30534/ijatcse/2020/52942020

10. K.I. Kyivska, S.V.Tsiutsiura, M.I.Tsiutsiura, O.V. Kryvoruchko, A.V.Yerukaiev and V.V.Hots. A study of the concept of parametric modeling of construction objects, International Journal of Advanced Research in Engineering and Technology, Volume 10, Issue 2, 2019, pp 636-646.

11. Y. Riabchun, T. Honcharenko, V. Honta, K. Chupryna, O.Fedusenko. Methods and means of evaluation and development for prospective students' spatial awareness, International Journal of Innovative Technology and Exploring Engineering, Volume 8, Issue 11, September 2019, pp. 4050-4058, https://www.ijitee.org/wp-content/uploads/papers/v8i11/ K15320981119.pdf

12. O. Shushura, L. Asieieva, I. Husyeva, M. Stepanov, O.Datsiuk. Construction of models for conversion of mortgage applications by the method of multiple regression and Neural Networks, International Journal of Advanced Trends in Computer Science and Engineering, 9(3), May-June 2020, pp. 2702-2707, https://doi.org/10.30534/ijatcse/2020/33932020

13. A. G. Myasnikov. Information and logical modeling in construction, International Journal of Advanced Trends in Computer Science and Engineering, 9(1), January -February 2020, pp. 304-307, https://doi.org/10.30534/ijatcse/2020/46912020

14. N. V. Danilina. Application of BIM-Technologies at the Stage of Urban Planning Design, Promyshlennoe $i$ grazhdanskoe stroitel'stvo [Industrial and Civil Engineering], 2018, no. 9, pp. 48-52. (In Russian)

15. A. Kuchansky, A. Biloshchytskyi, Yu.Andrashko, S. Biloshchytska, T. Honcharenko, V.Nikolenko. Fractal Time Series Analysis in Non-Stationary Environment, 2019 IEEE International Scientific-Practical Conference: Problems of Infocommunications Science and Technology, PIC S and T 2019 - Proceedings, 2019, pp. 236-240.

16. S.A.Biancardo, N. Viscione, A. Cerbone and E. Dessì. BIM-Based Design for Road Infrastructure: A Critical Focus on Modeling Guardrails and Retaining Walls, Infrastructures, 2020, 5, 59, https://doi.org/10.3390/infrastructures5070059.

17. R.Sacks, C.Eastman, G. Lee and P. Teicholz. BIM Handbook: A Guide to Building Information Modeling for Owners, Designers, Engineers, Contractors, and Facility Managers, 3rd ed.; John Wiley \& Sons: Hoboken, NJ, USA, 2018, p. 688.
18. D. Chernyshev, D.Ryzhakov, O. Dikiy, O. Khomenko and S.Petrukha. Innovative Technology for Management Tools of Commercial Real Estate in Construction, International Journal on Emerging Trends in Engineering Research, 8(9), September 2020, pp. 4967-4973, https://doi.org/10.30534/ijeter/2020/13892020 